\title{
Erratum to: Erosion and Flooding - Threats to Coastal Infrastructure in the Arctic: A Case Study from Herschel Island, Yukon Territory, Canada
}

\author{
Boris Radosavljevic $^{1,2} \cdot$ Hugues Lantuit ${ }^{1,2} \cdot$ Wayne Pollard $^{3} \cdot$ Paul Overduin $^{1}$. \\ Nicole Couture $^{4}$. Torsten Sachs ${ }^{5}$ - Veit Helm ${ }^{6}$ - Michael Fritz ${ }^{1}$
}

Received: 18 February 2016 / Accepted: 19 May 2016 /Published online: 24 May 2016

(C) Coastal and Estuarine Research Federation 2016

\section{Erratum to: Estuaries and Coasts}

DOI 10.1007/s12237-015-0046-0

In our original article, the modeled flooding potential states that the risk typologies were based on projected sea level elevations made by representative concentration pathways (RCPs) 2.6 and 8.5. We realized, however, that even though Fig. 7 in the original article represents areas prone to flooding with the given elevations, $0.31 \mathrm{~m}$ should have been subtracted from the flooding elevations to account for sea level rise that occurred

The online version of the original article can be found at http://dx.doi.org/ 10.1007/s12237-015-0046-0.

Boris Radosavljevic

boris.radosavljevic@awi.de

1 Research Unit Potsdam, Alfred Wegener Institute, Helmholtz Centre for Polar and Marine Research, Potsdam, Germany

2 Institute of Earth- and Environmental Science, University of Potsdam, Potsdam, Germany

3 Department of Geography and Centre for Climate and Global Change Research, McGill University, Montreal, Canada

4 Northern Canada Division, Geological Survey of Canada, Ottawa, Canada

5 GFZ German Research Centre for Geosciences, Potsdam, Germany

6 Alfred Wegener Institute for Polar and Marine Research, Helmholtz Centre for Polar and Marine Research, Bremerhaven, Germany between $\sim 1800$ and 2011, to represent the range of sea level rise projected by the Intergovernmental Panel on Climate Change (IPCC). Thus, by following the same methodology, we present an updated flooding potential map with the following risk typologies:

1. High: elevation range $0.0-0.1 \mathrm{~m}$. Areas subject to frequent flooding, incorporating the range of sea level projections by RCP2.6 and RCP 8.5 in 2031;

2. Moderate: elevation range $0.1-0.4 \mathrm{~m}$. Areas subject to flooding with water levels matching the range of RCP2.6 and RCP8.5 sea level projections in 2061; and

3. Low: elevations above $0.4 \mathrm{~m}$. Areas subject to flooding with water levels exceeding the elevation of sea level projected for 2061 .

In addition, although uncertainties in shoreline position were meticulously documented and propagated through the entire study, the errors were not included in the original Fig. 7. Following is an updated coastal geohazard map that contains the standard error of the shoreline movement rate estimate, as a measure of uncertainty of future shoreline position. The standard error was calculated by the Digital Shoreline Analysis System (Thieler et al. 2009), as follows:

$S E=\sqrt{\frac{\sum\left(y-y^{\prime}\right)^{2}}{n-2}}$ 


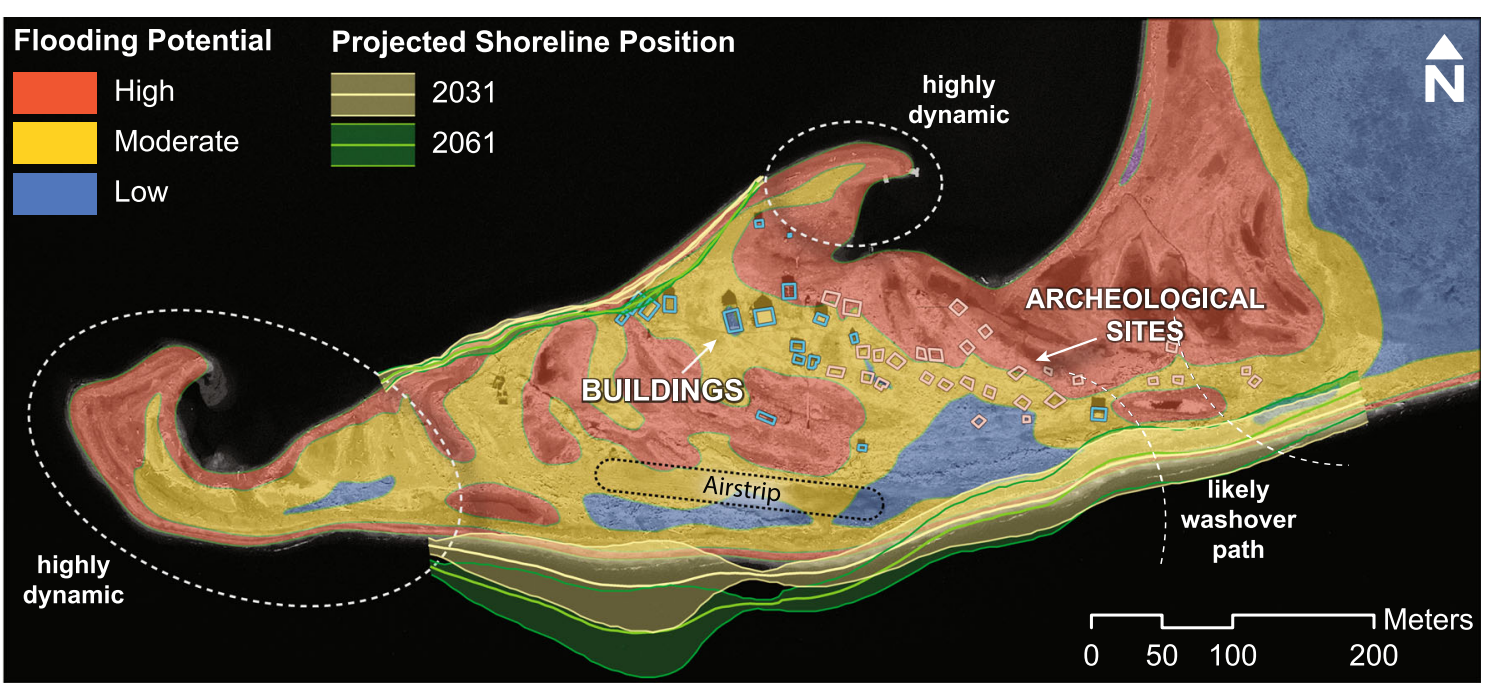

Fig. 7 Coastal geohazard map indicating flooding potential, projected shorelines with the associated standard error of the estimated shoreline movement rate, and dynamic areas with high hazard potential. These

Where $\mathrm{y}$ is the known distance from the baseline for a shoreline data point, $y^{\prime}$ is the predicted value based on the best-fit regression equation, and $\mathrm{n}$ represents the degrees of freedom. semi-transparent layers are superimposed on the 2011 image. Locations of buildings and archeological sites are highlighted as blue and peach colored rectangles

\section{Reference}

Thieler R.E., E.A. Himmelstoss, J.L. Zichichi, and A. Ergul. 2009. The Digital Shoreline Analysis System (DSAS) version 4. In 0 - an ArcGIS extension for calculating shoreline change. U. S. Geological Survey. 